\title{
Le concours
}

\section{Julia Vecsey}

Dr méd., membre de la FMH

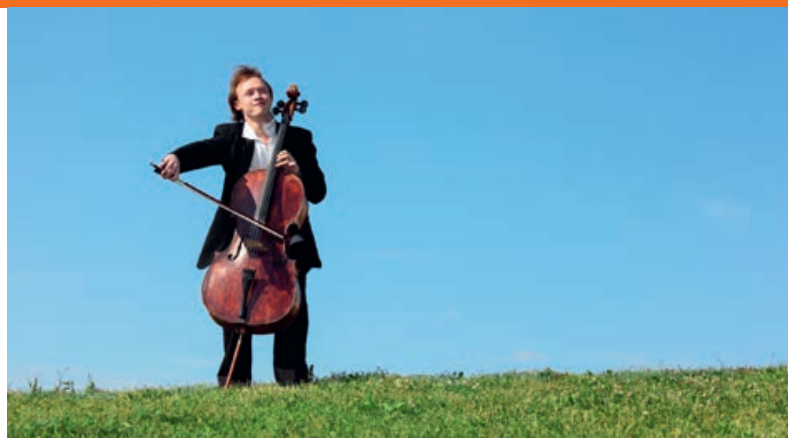

Il s'appelle Gordon, n'a qu'une passion, datant de son plus jeune âge, quand ses parents hongrois le surnommaient affectueusement Gordonka, qui signifie violoncelle dans cet idiome... ce qui a donc tout naturellement inspiré sa vocation.

Voilà donc plus de 17 ans que le jeune homme joue du violoncelle, travaille avec acharnement et s'améliore pour exceller; il progresse, participe à divers concours: le prochain auquel Gordon s'est inscrit doit avoir lieu à Ouagadougou, destination improbable pour une épreuve de musique classique, mais on n'arrête ni le progrès, ni la mondialisation!

Il habite Paris, sur les bords de la Seine (scène?), et un soir, à la nuit tombée, cherchant ses clés pour regagner son domicile, il est pris dans une manifestation de gilets jaunes; bousculé par la foule désorganisée, il se fait dérober son violoncelle, précieusement dissimulé dans son écrin!

Désespéré, il se rend à un poste de police voisin, se heurte à l'indifférence des fonctionnaires face à ce qui ne représente un drame que pour lui, et va remuer ciel et terre pour retrouver son instrument. Après quelques jours de vaines recherches, il tente de noyer son chagrin et ses espoirs dans différentes substances...

Il consomme notamment des champignons hallucinogènes. Lors d'un trip, où se mêlent rêve et réalité, il voit son instrument voler dans un avion dérouté de sa trajectoire pour partir à la recherche d'un sous-marin en perdition; il apprend que l'avion doit survoler la zone de navigation supposée du submersible, car, si le navire devait refaire surface, sauveteurs et matériel de secours pourraient très rapidement venir du ciel.

\section{Dans le même temps, Paris, toute l'Europe et les} villes côtières sont victimes de l'inévitable montée des eaux liée à la fonte des pôles et des glaciers.

Dans le même temps, Paris, toute l'Europe et les villes côtières sont victimes de l'inévitable montée des eaux liée à la fonte des pôles et des glaciers. L'appartement de Gordon devient momentanément inaccessible, et la meilleure décision que le musicien puisse prendre est de partir en personne à la recherche de l'instrument.

Suivant son instinct, ses rêves et les informations distillées par la presse, Gordon prend la voie des airs pour se rendre dans l'aérogare la plus proche du port d'attache du navire.

Ce terminal n'est qu'un seul parmi des milliers d'aéroports au monde, accueillant des millions d'avions qui laissent leurs traînées blanches dans le ciel avant d'atterrir à grand bruit, consommant des milliards de litres de kérosène qui aggravent le réchauffement climatique... La boucle est bouclée!

\section{Le rêve éveillé de Gordon n'était pas absurde!}

Le rêve éveillé de Gordon n'était pas absurde! Si le submersible est perdu corps et biens, disparu dans les profondeurs abyssales de l'océan, le violoncelle lui est effectivement retrouvé dans un aéroport, où il avait été abandonné par son voleur, qui le jugeait trop encombrant et surtout invendable...

Gordon le récupère donc avec soulagement, et décide dans la hâte de se rendre malgré tout à Ouagadougou pour participer au concours, comme initialement prévu. Cette période tourmentée est sans doute responsable de la confusion troublant l'esprit de Gordon: il doit interpréter la sarabande de la première suite de Bach devant le jury, mais il se trompe et leur joue... la courante... Il sera donc éliminé.

Malgré tout, médusé, surpris, éberlué, impressionné, envoûté, mais surtout enchanté par cette interprétation de génie, le jury ne peut que lui accorder le prix spécial du jury, consistant en un safari dans le parc de la Comoé, voisin de la capitale du Burkina Faso.

Gordon est ensorcelé par la faune et la flore africaines. Pour en voir plus, il décide d'aller plus loin, et part pour la Namibie avec son instrument sur le dos... Mais à la frontière, surprise et déception, on le refoule: notre génie était une fois de plus distrait, il n'avait pas de visa! Il est alors enfermé dans la geôle sommaire du poste frontière par des douaniers ventrus qui ne veulent rien entendre. Gordon sort alors son violoncelle, et leur interprète la courante qu'il avait jouée quelques jours plus tôt... A défaut d'entendre, les fonctionnaires écoutent, et eux aussi sont ensorcelés par la magie des sons. Ils laissent passer le prince de l'archet qui désormais aura le monde entier à ses pieds.

Crédit photo

(c) Pavel Losevsky | Dreamstime.com (image symbole) 